Davies, A. (1956). J. gen. Microbiol. 14, 425-439

\title{
Some Factors Affecting Lactase Formation and Activity in Saccharomyces fragilis
}

\author{
By A. DAVIES \\ Medical Research Council Unit for Chemical Microbiology, Department \\ of Biochemistry, Tennis Court Road, Cambridge
}

SUMMARY : A method for determining the lactase activity of Saccharomyces fragilis is described. The yeast is treated with cetyltrimethylammonium bromide, and the products of lactose hydrolysis are fermented with $S$. mandshuricus. The formation of lactase in $\boldsymbol{S}$. fragilis was studied by using the continuous culture technique. Lactase formation was inhibited by the presence of sugars in the medium at concentrations greater than $0.001 \%(w / v)$, but the magnitude of the inhibition and the range of activity over which it occurred depended on the nature of the sugar in the medium. With media containing glucose or sucrose, activities up to 10 units lactase $/ \mathrm{mg}$. dry weight were found when the sugar concentration was less than $0.001 \%(w / v)$, while at high concentrations lactase activity was almost completely absent. With media containing galactose or lactose at concentrations less than $0.001 \%(\mathrm{w} / \mathrm{v})$ activities of approximately 100 units lactase/mg. dry weight were observed, while at concentrations greater than $0.01 \%(\mathrm{w} / \mathrm{v})$ the activity was less. The mean generation time of the organisms and the concentrations of growth factors, ammonium and hydrogen ions had, over the range tested, no significant effect on lactase formation. The lactase activity found in intact organisms was always lower than the activity found in disrupted organisms, irrespective of the conditions under which the yeast had been grown. Possible interpretations of this phenomenon are discussed.

Lactase was isolated from a strain of Saccharomyces fragilis by Caputto, Leloir \& Trucco (1948) and its properties studied. They found that its optimum $\mathrm{pH}$ value was 6.8 and that it was activated by manganese, magnesium or potassium ions. Roberts \& McFarren (1953) studied the products of $S$. fragilis lactase action on lactose and found several oligosaccharides as well as glucose and galactose. R. Davies (unpublished results) found that a partially purified lactase preparation was activated by potassium ion and to a lesser extent by sodium ion, and that the activation by potassium ion was depressed by sodium ion. The latter worker also found that the lactase was unstable in water but fairly stable in solutions of potassium salts, the greatest stability being found in potassium phosphate buffer. In contrast to the lactase of Escherichia coli, however, little work appears to have been performed on the conditions which govern the formation of this enzyme in $S$. fragilis.

The advantages of the continuous culture technique for studying enzyme formation in micro-organisms have been described in a previous paper (A. Davies, 1956). The present paper describes investigations on the effect of certain sugars and other carbon sources on lactase formation in Saccharomyces fragilis. The effects of the mean generation time of the organism, the concentrations of ammonium and hydrogen ions and of growth factors have also been studied. 


\section{METHODS}

Organisms. Saccharomyces fragilis Jörgensen was obtained from the Centraalbureau voor Schimmelcultures, Delft; Saccharomyces mandshuricus (Saito, 1916) from the Carlsberg Laboratory, Copenhagen; Torulopsis pulcherrima from the National Collection of Type Cultures, London.

Growth conditions and analytical procedures. The preparation of the media and suspensions of organisms, analysis of growth media and the method of use of the chemostat were as described by Davies (1956). Saccharomyces mandshuricus for use in the estimation of lactase activity was grown for $18 \mathrm{hr}$. at $30^{\circ}$ in Roux bottles in the basal medium of Davies, Falkiner, Wilkinson \& Peel $(\mathbf{1 9 5 1})+2 \%(\mathrm{w} / \mathrm{v})$ galactose.

Determination of lactase activity. R. Davies (unpublished results) found that lactase activity of Saccharomyces fragilis was increased following certain treatments which either disrupted the organisms or damaged the cell wall. In order to follow the effect of various growth conditions on the lactase content of $S$. fragilis it was therefore necessary to measure the enzymic activity under conditions which would eliminate the masking effect of the cell wall. The method adopted depends on the fact that galactose-adapted $S$. mandshuricus is unable to ferment lactose but ferments quantitatively both the products of lactose hydrolysis. The detergent cetyltrimethylammonium bromide (CTAB) rapidly 'unmasks' the full lactase activity of $S$. fragilis, but the enzyme is rapidly denatured. However, the rate of denaturation is considerably decreased in a medium which contains a high concentration of lactose and potassium phosphate. On addition of $S$. mandshuricus the excess of CTAB is removed and gas evolution remains steady for long periods. Salton (1951) showed that bacteria can absorb up to half their dry weight of CTAB, though much smaller quantities exert a maximal effect on release of low molecular weight components from the cell. The action of detergents on micro-organisms seems to be dependent on the ratio of weight of detergent to weight of microorganism rather than on the concentration of the detergent (Gale \& Taylor, 1947, Salton, 1951). This explains why it is possible to disrupt $S$. fragilis with CTAB, a procedure which completely inhibits its fermentation system, and then by employing large amounts of $S$. mandshuricus to remove the excess CTAB from solution without seriously affecting the fermentation rate of the latter yeast.

The method used for routine determinations of activity was as follows: $\mathbf{0 . 3} \mathbf{m l}$. of a suspension of Saccharomyces fragilis was placed in the main compartment of a double side-arm Warburg manometer vessel, together with $0.2 \mathrm{ml}$. of $\mathrm{M}$-potassium phosphate buffer $(\mathrm{pH} \mathrm{6 \cdot 0)}$. One ml. of $10 \%(\mathrm{w} / \mathrm{v})$ lactose and $0.25 \mathrm{ml}$. of $0.4 \%(\mathrm{w} / \mathrm{v})$ CTAB were placed in one side-arm; $1.25 \mathrm{ml}$. of $S$. mandshuricus preparation were placed in the other side-arm. The latter preparation consisted of $25 \mathrm{ml}$. of a washed, aqueous suspension of $S$. mandshuricus (100 $\mathrm{mg}$. dry wt. organisms $/ \mathrm{ml}$.) to which $5 \mathrm{ml}$. M-potassium phosphate buffer ( $\mathrm{pH} \mathrm{6.0)}$ and $1 \mathrm{ml}$. 0.1 M-sodium azide were added; the preparation was then shaken for $3 \mathrm{hr}$. at $25^{\circ}$ to decrease the endogenous fermenta- 
tion. After equilibration at $\mathbf{2 5}^{\circ}$ the CTAB and lactose were tipped into the main compartment, the solutions thoroughly mixed and the $S$. mandshuricus preparation tipped a few seconds later. The variation between replicate estimations was $\pm 5 \%$. Lactase activity is expressed as $\mu$ mole lactose hydrolysed/ mg. dry wt. organisms $/ \mathrm{hr}$. The unit of enzyme is that amount of enzyme which will hydrolyse $1 \mu$ mole lactose in $1 \mathrm{hr}$. at $25^{\circ}$.

To check the results obtained by this procedure a second method was developed. Samples of Saccharomyces fragilis were measured into manometer cups and dried for $2 \mathrm{hr}$. over phosphorus pentoxide in vacuo (Lederberg, 1950). Phosphate buffer and the $S$. mandshuricus preparation were then added to the dried yeast and $1 \mathrm{ml} .10 \%(\mathrm{w} / \mathrm{v})$ lactose placed in the side-arm. The carbon dioxide evolved after tipping was measured at $25^{\circ}$. The activities obtained using this method varied from 80 to $100 \%$ of those observed when the CTAB procedure was used.

Fermentation rates were determined in Warburg manometers at $25^{\circ}$ according to the techniques of Umbreit, Burris \& Stauffer (1949), and were expressed in terms of $Q_{\mathrm{CO}_{2}}^{\mathrm{N}_{2}}=\mu \mathrm{l}$. $\mathrm{CO}_{2} / \mathrm{mg}$. dry wt. $/ \mathrm{hr}$.

Chemicals. Kerfoots Biochemical Reagent Sugars were used throughout; other chemicals were of analytical quality.

\section{RESULTS}

\section{Lactase formation during growth in shaken flasks}

The change in lactase content of Saccharomyces fragilis with time of growth under various conditions is shown in Fig. 1. Curves marked $A$ show lactase formation and growth in a medium initially containing $1.5 \%(\mathrm{w} / \mathrm{v})$ glucose, $352 \mathrm{mg}$. ammonia-N/l. and $20 \%$ of the standard amount of growth factors. The lactase content of the organisms remained low until growth had almost ceased and then rose rapidly to 4 units $/ \mathrm{mg}$. This rise in activity was concurrent with the disappearance of glucose from the medium. When the yeast was grown in a similar medium containing $0 \cdot 1 \%(\mathrm{w} / \mathrm{v})$ glucose, cell division ceased earlier and at a lower culture density than in the previous case. The lactase content was low at the beginning of the experiment and rose to approximately 3 units/ mg. during growth (Fig. 1, curves $B$ ).

With a medium containing $2 \%(\mathrm{w} / \mathrm{v})$ glucose, $105 \mathrm{mg}$. ammonia-N/l. and $20 \%$ of the standard concentration of growth factors, the culture density was decreased compared to a culture grown on a medium containing $352 \mathrm{mg}$. ammonia-N/l. The yeast took $39 \mathrm{hr}$. to exhaust the medium of its glucose. In these conditions the lactase content was low for most of the experiment (Fig. 1, curves $C$ ).

When growth factors were present in the medium at the standard concentrations, glucose utilization ceased when growth ceased. When $\boldsymbol{S}$. fragilis was grown in a medium containing growth factors at the standard concentrations, $2 \%(\mathrm{w} / \mathrm{v})$ glucose and either 105 or $352 \mathrm{mg}$. ammonia-N/l. the lactase content remained at a low level throughout the course of the experiment.

When the yeast was grown in the basal medium (352 mg. ammonia-N/1., 
$60 \%$ of the standard concentration of growth factors) plus $2 \%(\mathrm{w} / \mathrm{v})$ galactose, the lactase content rose during the early phases of growth, reaching 110 units/ mg. when the culture was $18 \mathrm{hr}$. old, i.e. about the end of the exponential phase, and then diminished towards the end of growth (Fig. 2).

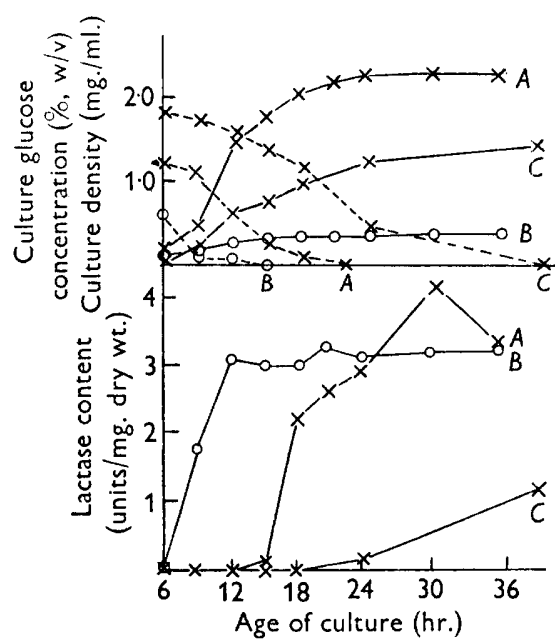

Fig. 1

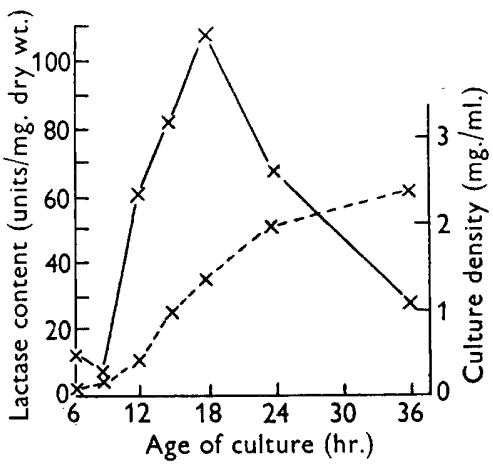

Fig. 2

Fig. 1. The effect on lactase content of Saccharomyces fragilis of growth for different periods of time in media containing various amounts of glucose and nitrogen. In top graph continuous lines=culture density, broken lines=culture glucose concentration. Curves $A: 1.5 \%(\mathrm{w} / \mathrm{v})$ glucose, $352 \mathrm{mg}$. ammonia-N/l., $20 \%$ of standard amounts of growth factors. Curves $B: 0 \cdot 1 \%(\mathrm{w} / \mathrm{v})$ glucose otherwise as curves $A$. Curves $C: 2 \cdot 0(\mathrm{w} / \mathrm{v})$ glucose, $105 \mathrm{mg}$. ammonia-N/1., $20 \%$ of the standard concentrations of growth factors. In curves $B$ the glucose concentration is plotted at 10 times its actual concentration for clarity.

Fig. 2. The effect on lactase content of growth for different periods of time in a medium containing $2.0 \%(\mathrm{w} / \mathrm{v})$ galactose, $352 \mathrm{mg}$. ammonia-N/l. and $60 \%$ of the standard amounts of growth factors. The continuous line represents the lactase content, the broken line represents the culture density.

\section{Lactase formation during growth in the chemostat}

Media containing glucose. When Saccharomyces fragilis was grown in a chemostat supplied with medium initially containing $9.5 \%(\mathrm{w} / \mathrm{v})$ glucose, $105 \mu \mathrm{g}$. ammonia- $\mathrm{N} / \mathrm{ml}$. and standard concentrations of growth factors, the glucose concentration in the culture became steady at approximately $8 \%$ $(\mathrm{w} / \mathrm{v})$, the nitrogen at approximately $20 \mu \mathrm{g} . / \mathrm{ml}$. and the lactase content of the resultant organisms was less than $0.1 \mathrm{unit} / \mathrm{mg}$. dry wt. at all mean generation times. Similar results were obtained when the reservoir medium contained $2 \%$ $(w / v)$ glucose; in this case the glucose concentration in the culture was always greater than $0.5 \%$ (w/v); the nitrogen concentration was less than $3 \mu \mathrm{g} . / \mathrm{ml}$. for all flow rates except that corresponding to a mean generation time of $\mathbf{1 \cdot 6} \mathrm{hr}$. where it rose to $7 \mu \mathrm{g} . / \mathrm{ml}$. In Fig. 3 lactase contents are plotted against mean generation time for organisms grown in media initially containing $0.5,0.25$ 
and $0 \cdot 1 \%(\mathrm{w} / \mathrm{v})$ glucose. In these cases the activity varied with the mean generation time but it could also be correlated with the glucose concentrations in the cultures. In Fig. 4, (compiled from the results of a large number of experiments) the lactase content is plotted against the logarithm of the glucose concentration in the culture for mean generation times of $3 \mathrm{hr}$. and $10 \mathrm{hr}$. The two curves are substantially the same, showing that the rate of cell division had little effect on lactase biosynthesis under these conditions. It would appear that lactase formation only occurred to a significant extent in media containing less than $0.001 \%(\mathrm{w} / \mathrm{v})$ glucose.

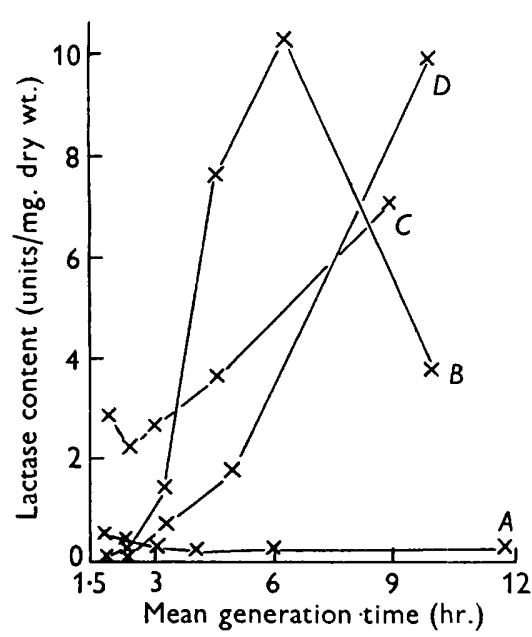

Fig. 3

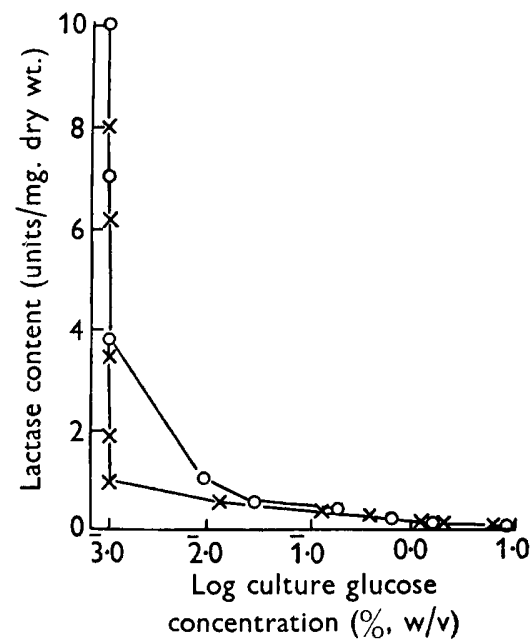

Fig. 4

Fig. 3. Variation of lactase content with mean generation time. Initial glucose concentrations $(\%, w / v)$ in basal medium: $A, 0.5 ; B, 0.25 ; C, 0.1$. Curve $D, 0.5 \%(\mathrm{w} / \mathrm{v})$ glucose, ammonia-N concentration of basal medium increased from 105 to $352 \mathrm{mg} . / \mathrm{l}$.

Fig. 4. Effect of culture glucose concentration and mean generation time on lactase content. Cells grown in basal medium + glucose with mean generation times of : $3 \mathrm{hr} .(\times-\times)$ and $10 \mathrm{hr} .(\mathrm{o}-\mathrm{o})$. The limit of sensitivity of the sugar analysis procedure is $0.001 \%$ $(w / v)$ glucose. Growth limited by nitrogen at glucose concentrations greater than $0.001 \%$, growth limited by glucose at glucose concentrations of $0.001 \%$ or less.

Effect of growth factors and nitrogen concentration. Growth in the chemostat can be controlled by decreasing the concentrations of growth factors. It is then possible to study the effect of growth factor deficiency and nitrogen and glucose excess. It was found that variations in nitrogen concentration or the nature of the growth factor which was limiting had little effect on the lactase content. The overriding effect of the steady-state glucose concentration in the culture is again shown in Fig. 5 in which the logarithm of the culture glucose concentration is plotted against the lactase content for the two cases $(a)$ where the nitrogen concentration was less than $2 \mu \mathrm{g} . / \mathrm{ml} .,(b)$ where it was greater than $10 \mu \mathrm{g} . / \mathrm{ml}$. The two curves are almost identical at glucose concentrations greater than $0.001 \%(\mathrm{w} / \mathrm{v})$ which is the limit of sensitivity of the sugar determination procedure. The hump on the second curve at $0 \cdot 6 \%(\mathrm{w} / \mathrm{v})$ 
glucose was obtained at long mean generation times when growth was limited by biotin deficiency. Since this rise in activity did not occur when growth was limited by deficiency of other growth factors, it is probably due to the specific conditions of growth under biotin deficiency at long mean generation times and not to the presence of excess nitrogen in the culture.

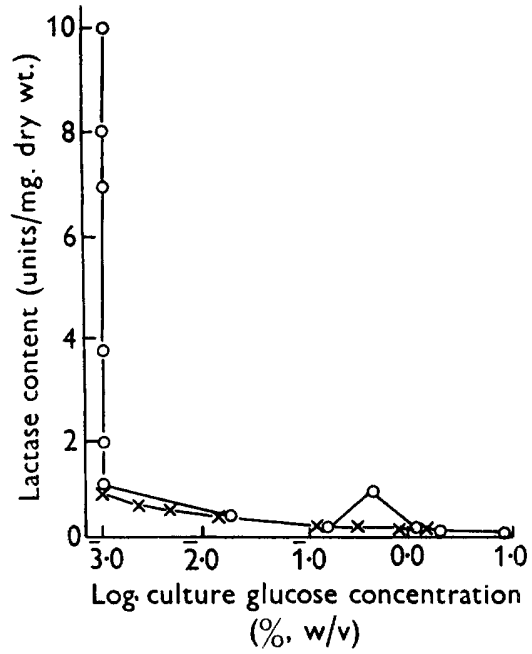

Fig. 5

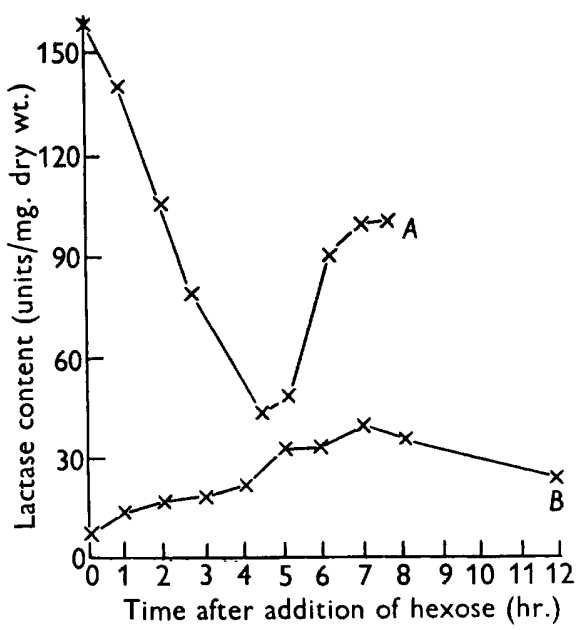

Fig. 6

Fig. 5. Effect of culture glucose concentration and nitrogen concentration on lactase content. Cells grown in basal medium + glucose. $\times-\times$, culture containing $<2$ mg. ammonia$\mathrm{N} /$ l., growth limited by nitrogen; $\mathrm{o}-\mathrm{o}$, culture containing $>10 \mathrm{mg}$. ammonia-N/1., growth limited by growth factors at glucose concentrations greater than $0.001 \%$, growth limited by glucose at glucose concentrations of $0.001 \%$ or less.

Fig. 6. Curve $A$ : effect of adding glucose at a final concentration of $1.0 \%$ to a culture growing on basal medium $+\mathbf{0 . 2} \%(\mathrm{w} / \mathrm{v})$ galactose with a mean generation time of $3.7 \mathrm{hr}$. Curve $B$ : effect of adding galactose to a final concentration of $1.0 \%(w / v)$ to a culture growing on basal medium $+0.1 \%(\mathrm{w} / \mathrm{v})$ glucose with a mean generation time of $3.5 \mathrm{hr}$.

Effect of the $\mathrm{pH}$ value of growth medium. The $\mathrm{pH}$ value of cultures in the chemostat varied between $\mathrm{pH} \mathbf{2 \cdot 6}$ and $3 \cdot 4$, depending on the concentration of sugar in the medium. However, by adding appropriate amounts of potassium hydroxide to the medium it was possible to grow the yeast over a wide range of $\mathrm{pH}$ values in media of otherwise similar composition. When the basal medium contained $0.1 \%(\mathrm{w} / \mathrm{v})$ glucose and the mean generation time was $4 \mathrm{hr}$., the lactase content increased from 8 to 11 units/mg. as the culture $\mathrm{pH}$ value was increased from $3 \cdot 4$ to $7 \cdot 7$. This difference was only twice that obtained when yeast was grown under constant cultural conditions in a $0.1 \%(\mathrm{w} / \mathrm{v})$ glucose medium. When the $\mathrm{pH}$ value of the culture was increased from $7 \cdot 7$ to $8 \cdot 3$ the lactase content decreased from 11 to 1.2 units/mg. This decrease could be accounted for by the increase in the culture glucose concentration from undetectably low concentrations at $\mathrm{pH} 7.7$ to $0.014 \%(\mathrm{w} / \mathrm{v})$ at $\mathrm{pH} 8.3$. It would appear that the $\mathrm{pH}$ value per se had little effect on the lactase content under conditions in the chemostat. 
When growth occurred on a $2 \%(w / v)$ glucose medium at a mean generation time of $3.5 \mathrm{hr}$. the lactase content increased from $0.1 \mathrm{unit} / \mathrm{mg}$. at $\mathrm{pH} 2.6$ to 1.0 unit/mg. at $\mathrm{pH} \mathrm{7.2}$. When the activities found in the $0.1 \%(\mathrm{w} / \mathrm{v})$ glucose culture are compared with those found in the $2 \%(\mathrm{w} / \mathrm{v})$ glucose culture it is clear that the inhibitory effect of glucose on lactase formation is present at all $\mathrm{pH}$ values.

Growth in the chemostat in media containing sugars other than glucose

Sucrose. When Saccharomyces fragilis was grown in the basal medium $+1 \%(\mathrm{w} / \mathrm{v})$ sucrose the lactase content varied from 0.03 to $0.2 \mathrm{unit} / \mathrm{mg}$., while when growth occurred in the basal medium initially containing $0 \cdot 2 \%(\mathrm{w} / \mathrm{v})$ sucrose the lactase content decreased from 8.7 units/mg. at a mean generation time of $8 \cdot 3 \mathrm{hr}$. to $0.6 \mathrm{unit} / \mathrm{mg}$. at a mean generation time of $1.6 \mathrm{hr}$. These values of lactase content could be correlated with the variations in concentration of invert sugar in the culture (Table 1 ).

Table 1. Correlation of lactase content and invert sugar in the culture medium for Saccharomyces fragilis grown in basal medium + sucrose

Saccharomyces fragilis was grown in chemostat in basal medium + initially $0 \cdot 2 \%(\mathrm{w} / \mathrm{v})$ sucrose. Lactase content determined by measuring carbon dioxide production from lactose in presence of $S$. mandshuricus and CTAB-treated $S$. fragilis. Invert sugar concentration determined by the method of Davies (1956).

$\begin{array}{llllll}\text { Mean generation time (hr.) } & 8.3 & 4.4 & 2.75 & 2.15 & 1.60 \\ \begin{array}{l}\text { Lactase content (units/mg. dry wt. } \\ \text { S. fragilis) }\end{array} & 8.7 & 3.0 & 2.5 & 1.0 & 0.6 \\ \begin{array}{l}\text { Invert sugar concentration } \\ (\%, \text { w } / \mathrm{v})\end{array} & <0.001 & <0.001 & 0.002 & 0.004 & 0.01\end{array}$

Table 2. Correlation of lactase content and sugar concentration in the culture for Saccharomyces fragilis grown in the chemostat in basal media +lactose

Sugar concentrations were determined by fermentation with Saccharomyces fragilis (Davies, 1956). Lactase was estimated as in Table 1.

(a) Medium initially containing $1 \%(\mathrm{w} / \mathrm{v})$ lactose

$\begin{array}{lccccc}\text { Mean generation time (hr.) } & 1 \cdot 70 & 2 \cdot 20 & 3 \cdot 4 & 5 \cdot 3 & 13 \cdot 8 \\ \text { Lactase content (units/mg.) } & 21 & 27 & 35 & 19 & 17 \\ \text { Sugar concentration (\%, w/v) } & 0.60 & 0 \cdot 43 & 0 \cdot 10 & 0 \cdot 26 & 0.09\end{array}$

(b) Medium initially containing $0 \cdot 2 \%(\mathrm{w} / \mathrm{v})$ lactose

$\begin{array}{lccccc}\text { Mean generation time (hr.) } & 1.70 & 2 \cdot 20 & 2.90 & 4.9 & 10.6 \\ \text { Lactase content (units/mg.) } & 28 & 32 & 56 & 65 & 100 \\ \text { Sugar concentration }(\%, \mathrm{w} / \mathrm{v}) & 0.008 & 0.013 & 0.004 & <0.001 & <0.001\end{array}$

Lactose and galactose. The values of lactase content found in Saccharomyces fragilis grown in basal media + lactose or galactose showed a twofold to tenfold increase over those found in basal media + growth-limiting amounts of glucose. This suggests, but does not prove, that lactose and galactose induced lactase formation by this organism. In Table 2 the relation between lactase content 
and residual sugar in the culture is shown for growth on basal media containing $\mathbf{1 . 0} \%$ and $\mathbf{0 . 2} \%(\mathrm{w} / \mathrm{v})$ lactose at various mean generation times, and it will be seen that the lactase content decreased as the steady state concentration of sugar in the medium increased. The nature of the sugar in the medium was not determined in either of these experiments, but evidence is presented in a later paragraph that it consisted of a mixture of lactose, glucose and galactose. It is not possible to state whether lactose itself has any inhibitory effect on lactase formation since the glucose in the culture might account for the observed reduction in enzymic activity. From a comparison of the activities found in the cultures grown in the $0.2 \%(\mathrm{w} / \mathrm{v})$ and the $1.0 \%(\mathrm{w} / \mathrm{v})$ lactose media it would appear that a concentration of sugar equivalent to $0.01 \%$ $(\mathrm{w} / \mathrm{v})$ lactose in the culture exerted an almost maximal inhibitory effect on

Table 3. Correlation of lactase content and galactose concentration in the culture for yeast grown in the chemostat in basal media + galactose

Sugar concentrations were determined by fermentation with Saccharomyces fragilis (Davies, 1956). Lactase was estimated as in Table 1.

(a) Medium initially containing $1.0 \%(\mathrm{w} / \mathrm{v})$ galactose

$\begin{array}{lccccc}\text { Mean generation time (hr.) } & 1 \cdot 70 & 2 \cdot 35 & 3 \cdot 2 & 5 \cdot 6 & 9 \cdot 8 \\ \text { Lactase content (units } / \mathrm{mg} .) & \mathbf{3 1} & \mathbf{3 9} & \mathbf{4 0} & \mathbf{3 3} & \mathbf{4 0} \\ \text { Sugar concentration }(\%, \mathrm{w} / \mathrm{v}) & \mathbf{0 . 7 4} & \mathbf{0 . 5 2} & \mathbf{0 . 4 9} & \mathbf{0 . 3 6} & 0 \cdot 21\end{array}$

(b) Medium initially containing $0 \cdot 2 \%(\mathrm{w} / \mathrm{v})$ galactose

$\begin{array}{llllrr}\text { Mean generation time (hr.) } & \mathbf{1 . 7 0} & \mathbf{2 \cdot 4 0} & \mathbf{3 . 2} & \mathbf{5 . 2} & 10 \cdot 3\end{array}$

$\begin{array}{llllll}\text { Lactase content (units/mg.) } & 41 & 82 & 102 & 101 & 126\end{array}$

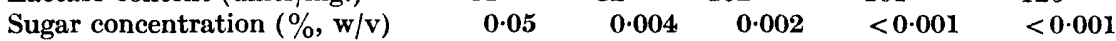

lactase formation. A similar dependence of lactase activity on sugar concentration was found for growth in galactose media under similar conditions (Table 3). Since the lactase content did not vary unduly with mean generation time for growth on both the $1.0 \%(\mathrm{w} / \mathrm{v})$ lactose and the $1.0 \%(\mathrm{w} / \mathrm{v})$ galactose media, it would appear that the rate of cell division had little effect on the formation of lactase.

Mixtures of glucose and galactose. The effect of adding glucose to an exponentially growing culture of Saccharomyces fragilis which had a high lactase content was demonstrated by the following experiment. From a culture growing with a mean generation time of $3.7 \mathrm{hr}$. in the basal medium $+0.2 \%(\mathrm{w} / \mathrm{v})$ galactose, a $10 \mathrm{ml}$. sample was collected. Glucose was then added directly to the culture to give a final concentration of $1.0 \%(\mathrm{w} / \mathrm{v})$. Further samples were collected at intervals and their lactase contents determined. There was an immediate and rapid decrease in the lactase content followed by a rise (Fig. 6). This experiment indicated that under these poorly regulated conditions an excess of glucose exerted an inhibitory effect on lactase formation. This diminution in activity does not necessarily imply that enzyme destruction was occurring, since a decrease in the activity of organisms collected from the chemostat would occur by a cessation of enzyme production coupled with continued growth. 
The effect of adding galactose to a final concentration of $1.0 \%(w / v)$ to a culture growing exponentially (mean generation time $3.5 \mathrm{hr}$.) in a $0.1 \%$ $(\mathrm{w} / \mathrm{v})$ glucose medium is shown in Fig. 6 (curve $B$ ). An increase of lactase content was observed. Thus galactose, in the presence of glucose, stimulated the formation of lactase.

Table 4. Effect on lactase content and lactose fermentation of grozeth of Saccharomyces fragilis in a medium containing various amounts of glucose and galactose

The organisms were grown in the chemostat with a mean generation time of $3 \cdot 3 \mathrm{hr}$. Lactase estimated as in Table 1.

\begin{tabular}{|c|c|c|c|c|c|c|}
\hline Input glucose $(\%, w / v)$ & 0.2 & $0 \cdot 199$ & $0 \cdot 198$ & $0 \cdot 193$ & $0 \cdot 183$ & $0 \cdot 167$ \\
\hline Input galactose $(\%, w / v)$ & $0 \cdot 0$ & 0.001 & 0.002 & 0.007 & 0.017 & 0.033 \\
\hline Lactase content (units/mg.) & $6 \cdot 5$ & $9 \cdot 4$ & $11 \cdot 1$ & $15 \cdot 7$ & $\mathbf{2 7} \cdot 5$ & $39 \cdot 0$ \\
\hline $\begin{array}{l}\text { Lactase content (expressed } \\
\text { as } Q_{\mathrm{CO}_{2}} \text { ) }\end{array}$ & 580 & 840 & 1000 & 1400 & 2500 & $\mathbf{3 5 0 0}$ \\
\hline $\begin{array}{l}\text { Lactose fermentation rate } \\
\left(Q_{\mathrm{CO}_{2}}^{N_{3}}\right)\end{array}$ & $5 \cdot 5$ & 13 & 19 & 43 & 43 & 53 \\
\hline $\begin{array}{l}\text { Glucose fermentation rate } \\
\left(Q_{\mathrm{CO}_{2}}^{\mathrm{N}_{2}}\right)\end{array}$ & 22 & 24 & 32 & 56 & 50 & 52 \\
\hline Input glucose $(\%, w / v)$ & $0 \cdot 2$ & $0 \cdot 18$ & $0 \cdot 15$ & $0 \cdot 11$ & & \\
\hline Input galactose $(\%, w / v)$ & $0 \cdot 0$ & $0 \cdot 02$ & $0 \cdot 05$ & $0 \cdot 09$ & & \\
\hline Lactase content (units/mg.) & $5 \cdot 7$ & 36 & 64: & 102 & & \\
\hline $\begin{array}{l}\text { Lactase content (expressed } \\
\text { as } Q_{\mathrm{CO}_{3}} \text { ) }\end{array}$ & 510 & 3200 & 5600 & 9200 & & \\
\hline $\begin{array}{l}\text { Lactose fermentation rate } \\
\left(Q_{\mathrm{CO}_{2}}^{\mathrm{N}_{2}}\right)\end{array}$ & $8 \cdot 0$ & 50 & 48 & 40 & & \\
\hline $\begin{array}{l}\text { Glucose fermentation rate } \\
\left(Q_{\mathrm{CO}_{2}}^{\mathrm{N}_{3}}\right)\end{array}$ & 30 & 47 & 46 & 36 & & \\
\hline
\end{tabular}

By arranging two supplies of medium into one chemostat it was possible to obtain media containing various ratios of glucose and galactose, whilst maintaining the total hexose and all other constituents of the medium constant. The results are given in Table 4 . With a medium containing $0.007 \%(\mathrm{w} / \mathrm{v})$ galactose in a total hexose concentration of $0.2 \%(\mathrm{w} / \mathrm{v})$ a $250 \%$ increase in lactase content over the value found in a $0.2 \%(\mathrm{w} / \mathrm{v})$ glucose medium was observed. The lactase content steadily increased as the ratio of glucose to galactose was decreased. With a medium initially containing $0.09 \%(\mathrm{w} / \mathrm{v})$ galactose and $0.11 \%(\mathrm{w} / \mathrm{v})$ glucose the lactase content reached $102 \mathrm{units} / \mathrm{mg}$., a value not much smaller than that observed in a $0 \cdot 2 \%(\mathrm{w} / \mathrm{v})$ galactose medium. When galactose was added to cultures growing in media containing glucose in concentrations greater than $\mathbf{0 \cdot 2} \%(\mathrm{w} / \mathrm{v})$ little effect on the lactase content was observed (Table 5).

Growth in other carbon sources. Because of the low growth rates of Saccharomyces fragilis in the presence of the compounds examined (Davies, 1956) cultures were grown in Roux bottles in basal medium $+1 \%(\mathrm{w} / \mathrm{v})$ of the sodium salts of the substances listed below as carbon sources and the lactase content determined after various periods of growth.

With acetate the lactase content varied from $7 \cdot 2$ to $8 \cdot 7$ units/mg. This variation is not significant. With citrate the lactase content increased from 
$3 \cdot 1$ units/mg. in the early phases of growth to a maximum of $7 \cdot 7$ units/mg. $24 \mathrm{hr}$. after maximum growth was obtained and then decreased to $4 \cdot 8 \mathrm{units} / \mathrm{mg}$. With lactate the lactase content decreased from 2.9 units/mg. in 'young' (18 hr.) cultures to $1 \cdot 6$ units/mg. in the phase of exponential growth and then increased again when growth ceased. With succinate the lactase content increased from 3.2 units $/ \mathrm{mg}$. at the beginning of growth to a maximum of $5 \cdot 4$ units/mg. when maximum growth was attained. With $1 \%(\mathrm{v} / \mathrm{v})$ ethanol the lactase content was 8-10 units/mg. in cultures in the lag and early logarithmic phases of growth, then steadily decreased to $1 \mathrm{unit} / \mathrm{mg}$. during the later stages of growth. With glycerol $(1 \%, w / v)$ the lactase content remained steady at $6 \cdot 6$ units/mg. until growth ceased when there was a decrease to $1 \cdot 3$ units/mg.

\section{Table 5. Effect of ratio of glucose to galactose on lactase content}

Saccharomyces fragilis was grown in the chemostat in basal medium + various ratios of glucose to galactose. Culture hexose was estimated by fermentation with $S$. fragilis. Lactase estimated as in Table 1.

$\begin{array}{ccccc}\begin{array}{c}\text { Mean generation } \\ \text { time (hr.) }\end{array} & \begin{array}{c}\text { Initial glucose } \\ (\%, w / v)\end{array} & \begin{array}{c}\text { Initial galactose } \\ (\%, w / v)\end{array} & \begin{array}{c}\text { Culture hexose } \\ (\%, w / v)\end{array} & \begin{array}{c}\text { Lactase content } \\ \text { (units/mg.) }\end{array} \\ 3 \cdot 3 & 2 \cdot 0 & 0 \cdot 0 & 1 \cdot 2 & 0 \cdot 03 \\ 3 \cdot 4 & 1 \cdot 87 & 0 \cdot 013 & 0 \cdot 80 & 0 \cdot 1 \\ 3 \cdot 3 & 1 \cdot 67 & 0 \cdot 033 & 0 \cdot 64 & 0 \cdot 03 \\ 3 \cdot 3 & 0 \cdot 86 & 0 \cdot 11 & 0 \cdot 12 & 1 \cdot 1 \\ 3 \cdot 3 & 0 \cdot 62 & 0 \cdot 14 & 0 \cdot 13 & 0 \cdot 1\end{array}$

\section{Lactose fermentation and hydrolysis by intact Saccharomyces fragilis}

When Saccharomyces fragilis was grown in the basal medium + galactose or lactose in either the chemostat or in Roux bottles, the rate of lactose fermentation was approximately equal to the rate of glucose fermentation, irrespective of the concentration of sugar in the medium or the rate of division (Table 6).

Table 6. Fermentation rates for different sugars by Saccharomyces fragilis

Yeast grown in the chemostat at two different mean generation times in basal medium + lactose or galactose.

\begin{tabular}{|c|c|c|c|}
\hline $\begin{array}{c}\text { Initial sugar } \\
\text { concentration in } \\
\text { medium }\end{array}$ & $\begin{array}{c}Q_{\mathrm{CO}_{\mathbf{2}}}^{\mathbf{N}_{\mathbf{2}}} \\
\text { (glucose) }\end{array}$ & $\begin{array}{c}Q_{\mathrm{CO}_{2}}^{\mathrm{N}_{\mathbf{2}}} \\
\text { (lactose) }\end{array}$ & $\begin{array}{c}Q_{\mathrm{CO}_{2}}^{\mathrm{N}_{\mathbf{2}}} \\
\text { (galactose) }\end{array}$ \\
\hline \multicolumn{4}{|l|}{$0.2 \%$ lactose } \\
\hline (a) & 110 & 110 & 8 \\
\hline (b) & $\gamma 0$ & 60 & 10 \\
\hline \multicolumn{4}{|l|}{$1.0 \%$ lactose } \\
\hline (a) & 55 & 40 & 9 \\
\hline (b) & 125 & 120 & 65 \\
\hline \multicolumn{4}{|l|}{$0.2 \%$ galactose } \\
\hline (a) & 35 & 30 & 20 \\
\hline (b) & 60 & 50 & 15 \\
\hline \multicolumn{4}{|l|}{$1.0 \%$ galactose } \\
\hline (a) & 75 & 65 & 20 \\
\hline (b) & 175 & 150 & 55 \\
\hline
\end{tabular}

$(a)=$ organisms grown at $c .10 \mathrm{hr}$. mean generation time. $(b)=$ organisms grown at c. $1.7 \mathrm{hr}$. mean generation time. 
When $S$. fragilis was grown in media containing an excess of glucose, lactose was not fermented. When the yeast was grown with a mean generation time of $3.3 \mathrm{hr}$. in a medium initially containing $0.2 \%(\mathrm{w} / \mathrm{v})$ glucose, the organisms possessed lactase contents of $5 \cdot 7,6 \cdot 1,6 \cdot 4,6 \cdot 5$ and $6 \cdot 6$ units/mg., respectively, in five separate experiments. If the fermentation rates were determined by the lactase content these values would correspond to $Q_{\mathrm{Co}_{2}}^{\mathrm{N}_{2}}$ (lactose) $=510,550$, $570,580,590$. The observed values for $Q_{\mathrm{Co}_{\mathrm{a}}}^{\mathrm{N}}$ (lactose) were $8 \cdot 0,6 \cdot 3,6 \cdot 3,5 \cdot 5$, 7.0. The $Q_{\mathrm{Co}_{2}}^{\mathrm{N}_{2}}$ (glucose) values for these organisms were $30,32,49,22$, and 26 , respectively.

Partial replacement of glucose by galactose (even at low concentration) in a medium initially containing $0.2 \%(\mathrm{w} / \mathrm{v})$ glucose resulted in an increased rate of fermentation of lactose and of lactase activity (Table 4).

That the products of lactase action on lactose are glucose and galactose was demonstrated in the following way. Washed organisms from a culture of Saccharomyces fragilis grown on a medium containing $2 \%(\mathrm{w} / \mathrm{v})$ lactose were dried over phosphorus pentoxide for $2 \mathrm{hr}$. in vacuo, resuspended in phosphate buffer and incubated with $3 \%(\mathrm{w} / \mathrm{v})$ lactose for $30 \mathrm{~min}$. at $25^{\circ}$. The yeast was removed by centrifugation and the sugars in the supernatant separated by single dimensional paper chromatography on Whatman no. 1 paper using ethyl acetate/pyridine/water $(2: 1: 2)$ (Jermyn \& Isherwood, 1949) as the solvent. The chromatograms were developed for $15 \mathrm{hr}$. at room temperature, dried, and the positions of the sugars located with aniline hydrogen phthalate (Partridge, 1949). Sugars with $R_{F}$ values corresponding to lactose, glucose and galactose markers were found on the chromatogram; no other sugars were found.

Since Saccharomyces fragilis grown on a medium containing limiting concentrations $(<0 \cdot 25 \%, w / v)$ of glucose possessed lactase contents of up to 10 units/ mg. (equivalent to $Q_{\mathrm{Co}_{2}}^{\mathrm{N}_{2}}=900$ ), yet was unable to ferment lactose with a $Q_{\mathrm{Co}_{3}}^{\mathrm{N}_{2}}$ value greater than $8 \cdot 0$, although the rate of glucose fermentation was approximately four times this value, it would appear that the lactase was almost inactive in the intact organisms. A similar situation exists in organisms grown in media containing galactose or lactose. The lactase contents of organisms grown in lactose or galactose media were 20-400 times greater than those necessary to account for the rates of fermentation, while the rate of lactose hydrolysis by intact organisms (measured by the rate of lactose fermentation in the presence of $100 \mathrm{mg}$. of galactose-adapted $S$. mandshuricus) was little greater than the rate of fermentation. Table 7 gives the results of two experiments in which the lactase contents and the rate of lactose hydrolysis by intact organisms were compared for organisms grown in Roux bottles in basal media + lactose. It will also be seen that the rates of fermentation and hydrolysis of lactose by intact organisms showed little variation between $\mathrm{pH} 3 \cdot 0$ and 6.0, whereas lactase in disrupted organisms was inactive at $\mathrm{pH} \mathrm{3 \cdot 0.} \mathrm{In} \mathrm{this}$ experiment the lactase content was determined on vacuum-dried $S$. fragilis, but CTAB-treated organisms behaved similarly.

With intact organisms the rate of hydrolysis of lactose slightly exceeds the rate of fermentation. To determine the nature of the sugars released into the 
medium a thick (100 mg. dry wt./ml.) suspension of $S$. fragilis was allowed to ferment lactose for varying periods of time. Samples were centrifuged at $3000 \mathrm{~g}$ and the supernatant fluids run on paper chromatograms in ethyl acetate/pyridine/water. Before all the lactose had been utilized sugars with $\boldsymbol{R}_{\boldsymbol{F}}$ values corresponding to lactose, glucose and galactose were detected. Visual comparison of the size and intensity of the glucose and galactose spots indicated that approximately equivalent amounts of these two sugars were present.

Galactose fermentation. Saccharomyces fragilis, grown in a medium containing an excess of glucose, was unable to ferment galactose. When the medium contained growth-limiting amounts of glucose the rate of galactose fermentation varied from zero to $Q_{\mathrm{NO}_{\mathbf{z}}}^{\mathrm{N}_{3}}=\mathbf{3 \cdot 0}$. When the yeast was grown in a medium containing lactose or galactose, the rate of galactose fermentation varied from 5 to $90 \%$ of the rate of lactose fermentation (Table 6).

\section{DISCUSSION}

The formation of lactase and of invertase by Saccharomyces fragilis is similar in many respects. The two processes resemble each other in their response to glucose in the culture medium, the amount of enzyme formed being small in media containing glucose at concentrations exceeding $0.01 \%(\mathrm{w} / \mathrm{v})$ and increasing simultaneously at concentrations lower than this. Figs. 4 and 5 include several points for lactase content at a concentration of $0.001 \%(\mathrm{w} / \mathrm{v})$ glucose; the points with the lower activities probably correspond to a higher concentration of glucose in the medium than the points at higher activities, but the precise glucose concentrations were not ascertained since they were below the limit of sensitivity of the sugar determination procedure. Lactase formation is stimulated by growth of $S$. fragilis in the presence of the enzyme substrate lactose as sole source of carbon. The stimulation is greater at lower substrate concentrations, suggesting that there is some inhibition of lactase formation by higher concentrations of lactose (Table 2). Galactose produces a similar response (Table 3). Invertase formation shows a similar dependence on sucrose concentration (Davies, 1956). Lactase formation, like invertase formation, is independent of the growth rate of $S$. fragilis and of the concentration of ammonia- $\mathrm{N}$ and growth factors. In media containing excess glucose the lactase content of $S$. fragilis increases with rise in $\mathrm{pH}$ value and in this respect lactase formation is again similar to invertase formation. However, when the medium contains limiting amounts of glucose increasing the $\mathrm{pH}$ value from 3.4 to $7 \cdot 7$ has no significant effect on lactase formation, whereas invertase formation is minimal at $\mathrm{pH} \mathbf{5 \cdot 4}$ and its activity increases as the $\mathrm{pH}$ departs from this value, and in this respect the two enzymes differ. The work of Wilkes \& Palmer (1932) and of Demis, Rothstein \& Meier (1954) suggests that invertase is associated with the surface of the organism. The much greater dependence on $\mathrm{pH}$ value of the lactase activity of disrupted organisms as compared with intact organisms (Table 7 ) suggests that the lactase of $S$. fragilis is separated from the environment by an osmotic barrier. The existence of such a barrier might also account for the increase in lactase activity observed 
on disruption of the organisms if it had a restricted permeability to lactose. The existence of ' permeability barriers ' was invoked by Deere (1939) to account for similar increases in lactase activity when Escherichia coli mutabile was disrupted. On the other hand, Myrbäck \& Vasseur (1943) suggested that at $\mathrm{pH}$ values where toluene-treated Torula utilis showed no lactase activity, fermentation of lactose by the intact organism must occur by some route not involving lactase. This explanation seems unlikely.

Table 7. Comparison of lactose hydrolysis in intact Saccharomyces fragilis with lactase content of disrupted organisms

$S$. fragilis was grown in Roux bottles in basal medium + lactose. In Expt. A the medium contained $2 \%(w / v)$ lactose initially, in Expt. B the initial lactose concentration was $1.0 \%$ $(\mathrm{w} / \mathrm{v})$. Washed suspensions were prepared and the lactase activity of vacuum-dried yeast, measured by carbon dioxide production from lactose in presence of $S$. mandshuricus, was compared with the rate of lactose hydrolysis by intact $S$. fragilis at different pH values. Results expressed as $\mu$ mole lactose hydrolysed or fermented/mg. dry wt. organisms/hr.

\begin{tabular}{|c|c|c|c|c|}
\hline Expt. $\ldots$ & A & B & B & B \\
\hline $\mathrm{pH}$ value for enzymic tests & $6 \cdot 0$ & $\mathbf{3} \cdot \mathbf{0}$ & $4 \cdot 0$ & $6 \cdot 0$ \\
\hline $\begin{array}{l}\text { Lactase activity at the above pH } \\
\text { values }\end{array}$ & 46 & $0 \cdot 05$ & $0 \cdot 15$ & 82 \\
\hline $\begin{array}{l}\text { Lactose hydrolysed by intact } S \text {. fragilis } \\
\text { at the above } \mathrm{pH} \text { values }\end{array}$ & $5 \cdot 5$ & $4 \cdot 2$ & $4 \cdot 8$ & $5 \cdot 3$ \\
\hline $\begin{array}{l}\text { Lactose fermented by intact } S \text {. fragilis } \\
\text { at the above pH values }\end{array}$ & $4 \cdot 3$ & $\mathbf{3 \cdot 9}$ & $4 \cdot 0$ & $4 \cdot 2$ \\
\hline
\end{tabular}

It is clear that growth of Saccharomyces fragilis in media containing lactose or galactose results in an increased formation of lactase and an increased rate of fermentation of lactose. If the rate of lactose utilization is partly controlled by the rate of migration across some barrier it is conceivable that growth in lactose or galactose media might modify the properties of the barrier in a way which would permit a more rapid passage of lactose. An increased rate of lactose fermentation might then result without a parallel increase in lactase content. There is no experimental evidence in support of this. The ratio of $Q_{\mathrm{CO}_{3}}^{\mathrm{N}_{3}}$ (lactose) to lactase content (expressed as a $Q_{\mathrm{CO}_{2}}^{\mathrm{N}_{2}}$ value) varied from 0.01 to 0.03 for those cases where lactose was fermented at a slower rate than glucose and where, therefore, the rate is probably not limited by the rate of overall glycolysis (Table 4). This variation is probably not significant. The rate of lactose fermentation appears to be roughly proportional to the lactase content under these conditions.

The existence of an osmotic barrier is not the only mechanism which can be invoked to account for the apparent inactivity of over $90 \%$ of the lactase in Saccharomyces fragilis. Other possibilities are: $(a)$ the intracellular $\mathrm{pH}$ value is not optimal for lactase action; $(b)$ the ionic composition within the cell may not be optimal for lactase action; $(c)$ lactase may be in combination with a specific inhibitor within the organism; $(d)$ the physical state of lactase within intact organisms may be different from that after their disruption. With respect to $(a)$, the average $\mathrm{pH}$ value within cells of $S$. cerevisiae is around $5 \cdot 8$ (Conway \& Downey, 1950) which is close to the $\mathrm{pH}$ value $(6 \cdot 0)$ at 
which the lactase estimations were carried out in this work with $S$. fragilis and it seems unlikely that differences in hydrogen-ion concentration could account for the 10- to 30-fold difference in activity between intact and disrupted $S$. fragilis. It must be admitted, however, that we have no information regarding the local distribution of hydrogen ions within the organism; this also applies to the local distribution of potassium and sodium ions. The potassium-ion concentration of $S$. fragilis is of the order of $37.5 \mu \mathrm{g} . / \mathrm{mg}$. dry wt. corresponding to an average concentration of between $0 \cdot 1$ and $0.2 \mathrm{M}$ (R. Davies, unpublished results) which is sufficient for maximal lactase activity. This value for potassium-ion concentration agrees with the concentration worked out from the figure of $450 \mathrm{mg}$. potassium ion/100 g. baker's yeast found by Conway \& Breen (1945). Lactase activity in the presence of $0 \cdot 1 \mathrm{M}$ potassium ion is depressed by the addition of sodium ion. However, $0 \cdot 1 \mathbf{M}$ sodium ion only halves the activity ( $R$. Davies, unpublished results), and it seems unlikely that ionic imbalance can account for the difference in lactase activity of intact and disrupted $S$. fragilis. There is no evidence to support or refute possibilities $(c)$ and $(d)$, although Kaplan $(1954,1955)$ and Fraser \& Kaplan (1955) suggested that differences in activity of yeast catalase as between intact and disrupted organisms might be due to differences in the physical state of the enzyme.

The author wishes to express his thanks to the Medical Research Council for a Scholarship for Training in Research Methods, and to Dr R. Davies for much helpful advice and encouragement.

\section{REFERENCES}

Caputto, R., Leloir, L. F. \& Trucco, R. E. (1948). Lactase and lactose fermentation in Saccharomyces fragilis. Enzymologia, 12, 350.

Conway, E. J. \& Breen, J. (1945). An 'ammonia'-yeast and some of its properties. Biochem. J. 39, 368.

Conway, E. J. \& Downey, M. (1950). pH values of the yeast cell. Biochem. J. 47, 355.

Davies, A. (1956). Invertase formation in Saccharomyces fragilis J. gen. Microbiol. $14,109$.

Davies, R., Falkiner, E. A., Wilkinson, J. F. \& Peel, J. L. (1951). Ester formation by yeasts. 1. Ethyl acetate formation by Hansenula species. Biochem. $J$. 49, 58.

DeEre, C. J. (1939). On the activation of the lactase of Escherichia coli mutabile. J. Bact. 37, 473.

Demis, D. J., Rothstein, A. \& Meier, R. (1954). The relationship of the cell surface to metabolism. X. The localisation and function of invertase in the yeast cell. Arch. Biochem. Biophys. 48, 55.

Fraser, M. J. \& Kaplan, J. G. (1955). The alteration of intracellular enzymes. III. The effect of temperature on the kinetics of altered and unaltered yeast catalase. J. gen. Physiol. 38, 515.

Gale, E. F. \& TAYLOR, E. S. (1947). The assimilation of amino-acids by bacteria. 2. The action of tyrocidin and some detergent substances in releasing aminoacids from the internal environment of Streptococcus faecalis. J. gen. Microbiol. 1,77 . 
Jermyn, M. A. \& Isherwood, F. A. (1949). Improved separation of sugars on the paper partition chromatograms. Biochem. J. 44, 402.

KapLAN, J. G. (1954). The alteration of intracellular enzymes. II. The relation between the surface and the biological activity of altering agents. J. gen. Physiol. 38, 197.

KAPLAN, J. G. (1955). The alteration of intracellular enzymes. 1. Yeast catalase and the Euler effect. Exp. Cell Res. 8, 305.

LeDERBERG, J. (1950). The $\beta$-D-galactosidase of Escherichia coli K-12. J. Bact. 60, 381.

Myrbäck, K. \& VASSEUr, E. (1943). Über die Lactosegärung und die Lokalisation der Enzyme in der Hefezelle. Z. physiol. Chem. 277, 171.

Partridge, S. M. (1949). Aniline hydrogen phthalate as a spraying reagent for chromatography of sugars. Nature, Lond., 164, 443.

Roberts, H. R. \& McF ARREN, E. F. (1953). The formation of oligosaccharides during lactase hydrolysis of lactose. Arch. Biochem. Biophys. 43, 233.

Salton, M. R. J. (1951). The adsorption of cetyltrimethylammonium bromide by bacteria, its action in releasing cellular constituents and its bactericidal effects. J. gen. Microbiol. 5, 391.

Umbreit, W. W., Burris, R. H. \& Stauffer, J. F. (1949). Manometric Techniques and Tissue Metabolism. Minneapolis: Burgess Publishing Co.

Wilkes, B. G. \& Palmer, E. T. (1932). Similarity of the kinetics of invertase action in vivo and in vitro II. J. gen. Physiol. 16, 233.

(Received 7 October 1955) 